\title{
Efficacy and toxicity of methotrexate (MTX) monotherapy versus MTX combination therapy with non-biological disease-modifying antirheumatic drugs in rheumatoid arthritis: a systematic review and meta-analysis
}

\author{
W Katchamart, ${ }^{1,2}$ J Trudeau, ${ }^{3}$ V Phumethum, ${ }^{1}$ C Bombardier ${ }^{4,5}$
}

- Additional figures and appendixes are published online only at http://ard.bmj.com/ content/vol68/issue7

${ }^{1}$ Rheumatology Division, Department of Medicine, University of Toronto, Toronto, Ontario, Canada;

${ }^{2}$ Rheumatology Division, Department of Medicine, Siriraj Hospital, Mahidol University, Bangkok, Thailand; ${ }^{3}$ Hôspital Notre-Dame, Department of Rheumatology, Montreal, Canada; ${ }^{4}$ Division of Rheumatology and Department of Health Policy, Management, and Evaluation, University of Toronto, Toronto, Ontario, Canada; ${ }^{5}$ Division of Clinical Decision Making and Health Care, Toronto General Research Institute, University Health Network, Toronto, Ontario, Canada

Correspondence to:

Dr C Bombardier, Institute for Work and Health, 481 University Avenue, Suite 800, Toronto, Ontario M5G 2E9, Canada; claire.bombardier@utoronto.ca

Accepted 17 November 2008 Published Online First

3 December 2008

\begin{abstract}
Objective: To evaluate the efficacy and toxicity of methotrexate (MTX) monotherapy compared with MTX combination with non-biological disease-modifying antirheumatic drugs (DMARDs) in adults with rheumatoid arthritis.
\end{abstract}

Method: A systematic review of randomised trials comparing MTX alone and in combination with other nonbiological DMARDs was carried out. Trials were identified in Medline, EMBASE, the Cochrane Library and ACR/ EULAR meeting abstracts. Primary outcomes were withdrawals for adverse events or lack of efficacy. Results: A total of 19 trials (2025 patients) from 6938 citations were grouped by the type of patients randomised. Trials in DMARD naive patients showed no significant advantage of the MTX combination versus monotherapy; withdrawals for lack of efficacy or toxicity were similar in both groups (relative risk $(R R)=1.16$; $95 \% \mathrm{Cl} 0.70$ to 1.93$)$. Trials in MTX or non-MTX DMARD inadequate responder patients also showed no difference in withdrawal rates between the MTX combo versus mono groups ( $\mathrm{RR}=0.86 ; 95 \% \mathrm{Cl} 0.49$ to 1.51 and $\mathrm{RR}=0.75 ; 95 \% \mathrm{Cl} 0.41$ to 1.35$)$, but in one study the specific combination of MTX with sulfasalazine and hydroxychloroquine showed a better efficacy/toxicity ratio than MTX alone with $\mathrm{RR}=0.3(95 \% \mathrm{Cl} 0.14$ to 0.65$)$. Adding leflunomide to MTX non-responders improved efficacy but increased the risk of gastrointestinal side effects and liver toxicity. Withdrawals for toxicity were most significant with ciclosporin and azathioprine combinations.

Conclusion: In DMARD naive patients the balance of efficacy/toxicity favours MTX monotherapy. In DMARD inadequate responders the evidence is inconclusive. Trials are needed that compare currently used MTX doses and combination therapies.

Methotrexate (MTX) is among the most effective disease-modifying antirheumatic drugs (DMARDs) in rheumatoid arthritis (RA) with less toxicity and better tolerability. Unfortunately, MTX alone may not fully control disease activity. Increasingly, MTX is used in combination with other nonbiological DMARDs. ${ }^{1-3}$

Many MTX and traditional DMARDs combination regimens have been studied, but several important questions remain. ${ }^{4-6}$ What is the relative benefit and toxicity of MTX mono versus MTX combination with DMARDs? When should the combination DMARD therapy be used: initially or only after a trial of MTX monotherapy? Finally, which is the preferred combination DMARD strategy? These questions are particularly salient as formularies in many countries require the use of MTX mono and MTX combo therapies before reimbursing for the more expensive biological drugs. The objective of this paper was to systematically review randomised trials that compared MTX monotherapy with MTX in combination with other non-biological DMARDs. This manuscript is part of the $3 \mathrm{E}$ (Evidence, Expertise and Exchange) Initiative described in more details in the same issue of this journal.

\section{MATERIALS AND METHODS}

\section{Literature search}

We performed a search of electronic bibliographic databases including Medline (1950 to June week 3 2007), EMBASE (1980 to 2007 week 25) and the Cochrane Central Register of Controlled Trials (2nd quarter 2007) using a search strategy that combined terms for "rheumatoid arthritis", "methotrexate" and "randomised controlled trials" (full search strategy available online at http:// www.annrheumdis.com/supplemental). We also searched the abstracts of the Annual scientific meetings of the American College of Rheumatology (ACR) and European League Against Rheumatism (EULAR) from 2005 to 2007, the references lists of all relevant studies, letters and review articles, and all languages were included.

\section{Study selection}

Two reviewers (WK, JT) independently screened the titles and abstracts of the citations and retrieved relevant articles. The following selection criteria were used: (a) randomised controlled trials of MTX monotherapy versus MTX combined with other DMARDs of at least 12 weeks of trial duration (open-label extensions were excluded as well as studies comparing DMARDs not currently used-for example, oral gold); (b) patients with $\mathrm{RA} \geqslant 18$ years old; (c) data available on one or more of following prespecified outcomes: ACR core set ${ }^{8}$; ACR 20, 50 or 70 responses $^{9}$; ACR remission ${ }^{10}$; Disease Activity Score $(\mathrm{DAS})^{11}{ }^{12}$; EULAR response ${ }^{13}$; withdrawal due to lack of efficacy or adverse events (AEs); 
Figure 1 Results of the literature search and disposition of the potentially relevant studies. *Number is not equal to the sum of the number from each database owing to duplication among databases. ACR, American College of rheumatology; CCRT, Cochrane Central Register of Controlled Trials; DMARD, disease-modifying antirheumatic drug; EULAR, European League Against Rheumatism; MTX, methotrexate; RA, rheumatoid arthritis; $\mathrm{RCT}$, randomised controlled trial.
6938 titles and abstracts identified through searches

- Medline $n=1662$

- EMBASE $n=4591$

- CCRT $n=374$

- ACR and EULAR (2005-7) n= 311

- Hand search $n=0$

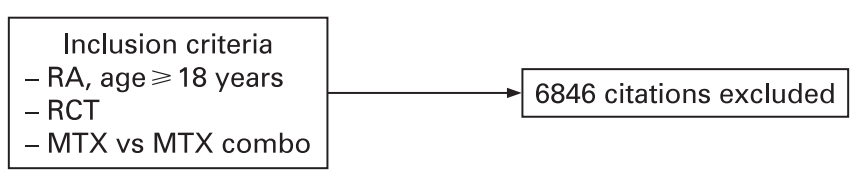

39 full-text articles retrieved ${ }^{*}$ (not in English)

- Medline $n=31$ (1)

- EMBASE $n=35(0)$

- CCRT $n=24$ (0)

- $A C R$ and EULAR abstract $n=2$

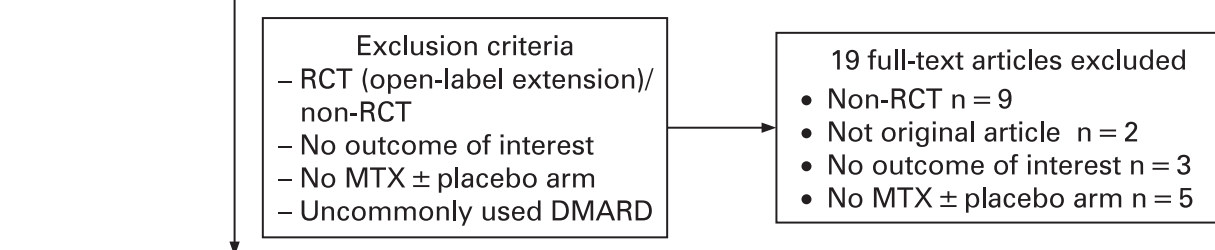

20 articles (19 studies) included

- Duplicate in all databases $n=16$

- EMBASE only $n=4$ number of total or individual AEs (only commonly reported individual AEs are presented).

\section{Data abstraction and quality assessment}

Two reviewers (WK, VP) independently extracted the data and assessed the quality of relevant studies. Study quality was assessed using van Tulder 's scale. ${ }^{14}$ This scale comprises 11

Table 1 Excluded studies and reason for exclusion

\begin{tabular}{|c|c|}
\hline Study & Reason for exclusion \\
\hline Calguneri, 1999 & $\begin{array}{l}\text { No methotrexate monotherapy arm (data combined with } \\
\text { sulfazalazine and hydroxychloroquine monotherapy) }\end{array}$ \\
\hline Clegg, 1997 & No outcome of interest \\
\hline Haagsma, 1995 & Summary of Haagsma et al. (included in this review) ${ }^{27}$ \\
\hline Kremer, 2004 & Open-label extension of randomised controlled trial \\
\hline Maillefert, 2003 & Open-label extension of randomised controlled trial \\
\hline Matucci-Cerinic, 2003 & Summary of Kremer et al. (included in this review) ${ }^{20}$ \\
\hline Mottaghi, 2005 & Non-randomised controlled trial \\
\hline Mroczkowski, 1999 & Open-label extension of randomised controlled trial \\
\hline Nagashima, 2006 & Non-randomised controlled trial \\
\hline Nisar, 1994 & Non-randomised controlled trial \\
\hline O’Dell, 1996 & Open-label extension of randomised controlled trial \\
\hline Rau, 1998 & Non-randomised controlled trial \\
\hline Stein, 1997 & Open-label extension of randomised controlled trial \\
\hline Trnavsky, 1993 & No methotrexate monotherapy arm \\
\hline Willkens, 1996 & $\begin{array}{l}\text { Published in the journal supplements and the key data have } \\
\text { been reported in Willkens et al (included in this review) }\end{array}$ \\
\hline $\begin{array}{l}\text { Krause D et al (German), } \\
1998\end{array}$ & Non-randomised controlled trial \\
\hline $\begin{array}{l}\text { Geokoop-Ruiterman } \\
\text { YPM, } 2005\end{array}$ & No MTX monotherapy arm \\
\hline $\begin{array}{l}\text { Geokoop-Ruiterman } \\
\text { YPM, } 2007\end{array}$ & No MTX monotherapy arm \\
\hline Mottonen T et al, 1999 & No MTX monotherapy arm \\
\hline
\end{tabular}

questions, including randomisation, blinding procedure (patients, provider and outcome assessor), concealed treatment allocation, similarity of the important baseline characteristics, co-intervention, timing of the outcome assessment, compliance and withdrawals and intention-to-treat analysis. Each item is rated as "yes" = 1 and "no or do not know" = 0 . The score ranges from 0 to 11 .

\section{Data synthesis}

We used RevMan 4.2.10 for analysis. The efficacy analysis was stratified into three groups based on previous DMARD use. The "DMARD naïve, parallel strategy" refers to trials in which patients who never received DMARDs (including MTX) were randomised to start MTX alone or MTX plus another DMARD; The "MTX inadequate response, step-up strategy" refers to trials in which patients with inadequate response to MTX were randomised to continue the use of MTX alone or to add a second DMARD. The "non-MTX DMARDs inadequate response, step-up strategy" refers to trials where patients with inadequate response to DMARDs (other than MTX) were randomly switched to MTX alone or MTX plus another DMARD. The toxicity analysis was stratified by DMARD combination and pooled across trials for each combination.

For continuous measures of efficacy, we used either end of trial data or change from baseline and pooled them as weighted mean differences using a random effect model. ${ }^{15}$ For the categorical measures of efficacy, the end of trial results were pooled and estimated using the relative risk (RR) with random effect model. An RR $>1$ favours MTX combination therapy. For the analysis of patient withdrawals, an RR $>1$ favours MTX monotherapy (MTX monotherapy results in less withdrawal than MTX combination). Our prespecified primary analysis was based on total withdrawal rates for efficacy or toxicity. 
Table 2 Characteristic of included studies

\begin{tabular}{|c|c|c|c|c|c|c|c|}
\hline \multirow[b]{2}{*}{ Study } & \multirow{2}{*}{$\begin{array}{l}\text { Sample } \\
\text { size }\end{array}$} & \multirow{2}{*}{$\begin{array}{l}\text { Study } \\
\text { duration } \\
\text { (months) }\end{array}$} & \multirow[b]{2}{*}{ Strategy* } & \multicolumn{2}{|c|}{ MTX (mg/week) } & \multirow[b]{2}{*}{ DMARD } & \multirow{2}{*}{$\begin{array}{l}\text { Quality } \\
\text { rating } \\
(0-11)\end{array}$} \\
\hline & & & & Mono & Combo & & \\
\hline Haagsma, $1997^{16}$ & 105 & 12 & DMARD-N & 15 & 7.5 & SSZ $3 \mathrm{~g} /$ day & 10 \\
\hline Dougados, $1999^{6}$ & 209 & 12 & DMARD-N & Up to 15 & Up to 15 & SSZ $3 \mathrm{~g} /$ day & 7 \\
\hline $\begin{array}{l}\text { Marchesoni, } \\
2003^{4}\end{array}$ & 61 & 12 & DMARD-N & 11.2 & 9.5 & CSA $2.5 \mathrm{mg} / \mathrm{kg} / \mathrm{day}$ & 8 \\
\hline Tascioglu, $2003^{5}$ & 70 & 12 & DMARD-N & 7.5 & 7.5 & SSZ 2 g/day & 5 \\
\hline Hetland, $2006^{17}$ & 160 & 12 & DMARD-N & 15 & 12.5 & CSA $2.5 \mathrm{mg} / \mathrm{kg} / \mathrm{day}$ & 9 \\
\hline $0^{\prime}$ Dell, $2006^{18}$ & 66 & 24 & DMARD-N & $7.5-17.5$ & $7.5-17.5$ & $\begin{array}{l}\text { DOXY } 20 \text { or } 100 \mathrm{mg} \\
\text { twice/day }\end{array}$ & 7 \\
\hline Tugwell, $1995^{19}$ & 148 & 6 & MTX-IR & 15 & 15 & CSA $2.5-5 \mathrm{mg} / \mathrm{kg} /$ day & 7 \\
\hline Kremer, $2002^{20}$ & 263 & 6 & MTX-IR & 16.1 & 16.8 & LEF $20 \mathrm{mg} / \mathrm{day}$ & 10 \\
\hline Lehman, $2005^{21}$ & 65 & 12 & MTX-IR & 18 & 18 & IM gold 50 mg/week & 8 \\
\hline Jarrett, $2005^{22}$ & 39 & 6 & MTX-IR & 11.9 & 14 & $\begin{array}{l}\text { Zolendronic acid } 5 \mathrm{mg} \\
\text { IV twice }\end{array}$ & 7 \\
\hline Ogrendik, $2007^{23}$ & 76 & 6 & MTX-IR & 17.5 & 15 & LEV 500 mg/day & 8 \\
\hline $\begin{array}{l}\text { Willkens, } 1992^{24} \\
1995^{25}\end{array}$ & 212 & 6 & Non-MTX-IR & $5-15$ & $5-15$ & AZA $50-150 \mathrm{mg} /$ day & 8 \\
\hline Ferraz, $1994^{26}$ & 82 & 6 & Non-MTX-IR & 7.5 & 7.5 & CQ $250 \mathrm{mg} /$ day & 9 \\
\hline Haagsma, $1994^{27}$ & 40 & 6 & Non-MTX-IR & 8.3 & 7.9 & SSZ 2 g/day & 7 \\
\hline O'Dell, $1996^{28}$ & 102 & 6 & Non-MTX-IR & $\begin{array}{l}\text { Up to } \\
17.5\end{array}$ & Up to 17.5 & $\begin{array}{l}\text { SSZ } 1 \mathrm{~g} / \text { day } \\
\text { HCO } 400 \mathrm{mg} / \text { day }\end{array}$ & 9 \\
\hline Hanyu, $1999^{29}$ & 37 & 60 & Non-MTX-IR & 7.5 & 5 & $\begin{array}{l}\text { Previous DMARD } \\
\text { (penicillamine, BUC, IM } \\
\text { gold) }\end{array}$ & 3 \\
\hline Ichikawa, $2005^{30}$ & 71 & 24 & Non-MTX-IR & 8 & 8 & BUC 200 mg/day & 7 \\
\hline Capell, $2007^{31}$ & 165 & 12 & Non-MTX-IR & 15 & 12.5 & SSZ 2 g/day & 8 \\
\hline Islam, $2000^{32}$ & 54 & 6 & Not clear & $7.5-15$ & & SSZ $2 \mathrm{~g} /$ day & 3 \\
\hline
\end{tabular}

Our analysis included data only from patients in the MTX + placebo and MTX+other DMARDS arms ( $n=158$ ).

*DMARD-N, disease-modifying antirheumatic drug naïve patients; MTX-IR, methotrexate inadequate response patients; non-MTXIR, non-MTX DMARDs inadequate response patients; †Van Tulder's scale.

AZA, azathioprine; BUC, bucillamine; CQ, chloroquine; CSA, ciclosporin; DOXY, doxycycline; HCO, hydroxychloroquine; IM gold, intramuscular gold; LEF, leflunomide; LEV, levofloxacin; SSZ, sulfasalazine.

The heterogeneity of the trials for each pooled analysis was estimated using the $\chi^{2}$ test and $\mathrm{I}^{2}$ test.

\section{RESULTS}

Our search retrieved 6938 citations. After review of titles and abstracts and removal of duplicates across databases, 39 full-text articles were retrieved for further evaluation and 20 articles (from 19 studies) were retained for our analysis (fig 1). Table 1 summarises the excluded studies and reason for exclusion.

\section{Characteristics of the included studies}

Table 2 gives the characteristics of the included studies. The total number of patients in the trials was 2025. Most of the trials were 6 or 12 months in duration. The doses of MTX ranged between 5 and $18 \mathrm{mg} /$ week but most were between 7 and $15 \mathrm{mg} /$ week. MTX was administered orally in all trials.

\section{Methodological quality of studies}

Ten studies ${ }^{16-18} 202124-262831$ demonstrated appropriate randomisation, adequate blinding of intervention in both patients and care providers as well as clearly reported number and reason for withdrawal and drop out. Seven of these $e^{16} 172024-2628$ were highquality (comparison groups had similar baseline characteristics and co-interventions and acceptable withdrawals and drop outs) but one study ${ }^{18}$ had a high drop-out rate ( $\left.\sim 59 \%\right)$. In two studies, ${ }^{21} 31$ there were unequal co-interventions including steroid or non-steroidal anti-inflammatory drugs (NSAIDs) between the treatment groups. One of these ${ }^{21}$ also had a high drop-out rate in the MTX + placebo group due to lack of efficacy ( $52 \%$ vs $24 \%$ in MTX vs MTX+gold, respectively).
In five studies, ${ }^{6} 19222330$ the method of randomisation was not explicitly described; additionally co-intervention was either unclear $^{619}$ or higher ${ }^{22}$ (NSAIDS or steroid) in the MTX treatment group

Owing to their open-label nature, five studies ${ }^{4} 272932$ were rated lower and in three the method of randomisation was also unclear. ${ }^{5} 2932$

\section{Efficacy \\ DMARD naïve, parallel design}

The ACR responses were available in three of the six trials that compared MTX mono with MTX combo therapies in MTX naïve patients (fig 2). These trials included a total of 287 patients. Combinations arms were MTX+ciclosporin $(\mathrm{CSA})^{4} 17$ and MTX+doxycycline, ${ }^{18}$ The only significant result was for the ACR 70 response in one CSA trial with $\mathrm{RR}=2.41$ (95\% CI 1.07 to 5.44) favouring the MTX combination arm.

The EULAR response was available in an additional two trials (368 patients) with combination of MTX+ sulfasalazine $(\mathrm{SSZ})^{616}$ or $\mathrm{MTX}+\mathrm{CSA}^{17}$ (fig A, online only). There was no significant difference between the two groups for a "good" or "moderate" EULAR response or remission.

The number of patients who withdrew owing to lack of efficacy was available in five of the six trials (405 patients) with combination of MTX+SSZ, $5616{\mathrm{MTX}+\mathrm{CSA}^{4}}^{4}$ and MTX+doxycycline $e^{18}$ (fig B, online only). MTX combination therapy resulted in less patient withdrawal than monotherapy but it was not significant $(\mathrm{RR}=0.63,95 \%$ CI 0.34 to 1.17$)$ furthermore, the number of patients who withdrew because of 
Figure 2 American College of Rheumatology (ACR) response: MTX combination vs MTX monotherapy in DMARD naïve group. CSA, ciclosporin; DMARD, disease-modifying antirheumatic methotrexate. drug; DOXY, doxycycline; MTX

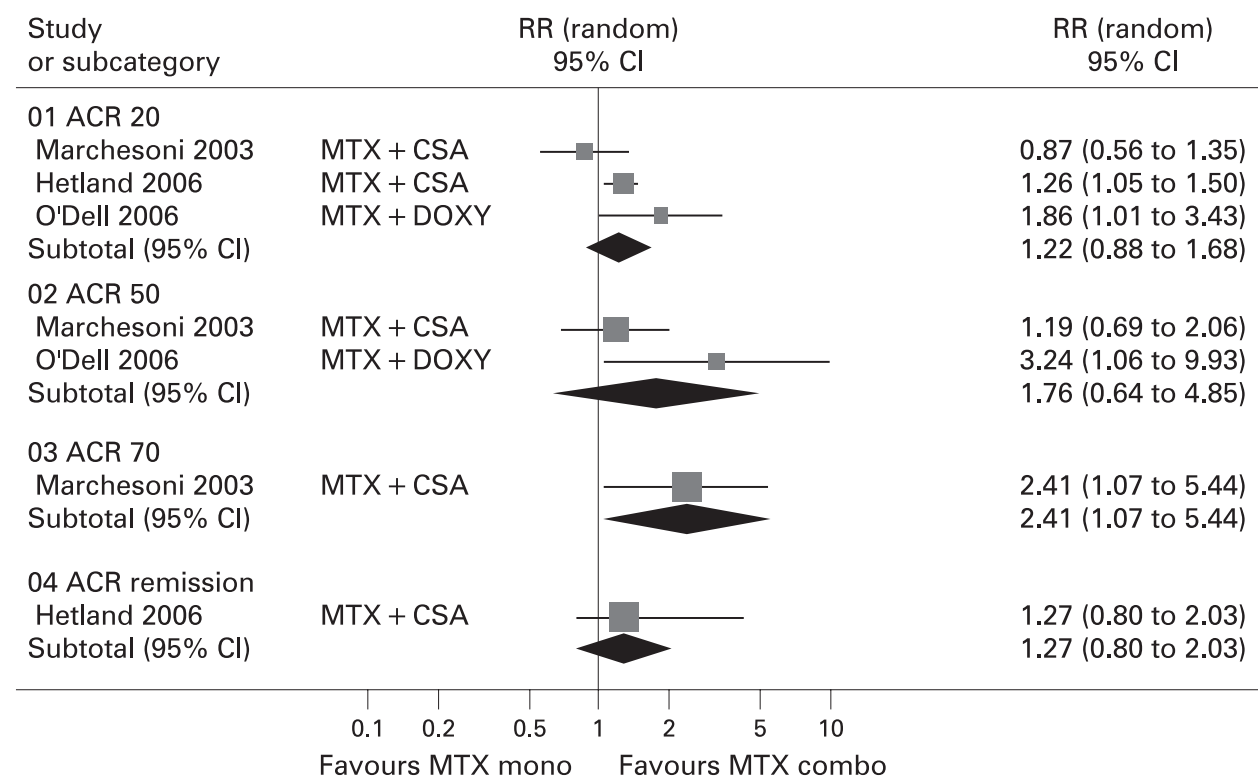

toxicity was significantly increased 1.72 (95\% CI 1.04 to 2.83 ) (fig C, online only).

\section{MTX inadequate response, step-up design}

The ACR responses were available in four of five trials $(552$ patients) that compared MTX mono with MTX combo therapies in MTX inadequate response patients (fig 3). Combination arms included MTX+leflunomide (LEF), ${ }^{20}$ MTX+CSA, ${ }^{19}$ MTX+ intramuscular gold (IM gold) ${ }^{21}$ and MTX+ levofloxacin. ${ }^{23}$ In this group of trials combination therapy was significantly more effective than MTX monotherapy with $\mathrm{RR}=2.51$ (95\% CI 1.92 to 3.28$), \mathrm{RR}=4.54(95 \%$ CI 2.51 to 8.20 ) and $\mathrm{RR}=5.59$ (95\% CI 2.08 to 15.01) for ACR 20, 50 and 70 response, respectively. There were no data on ACR remission and EULAR response.

The number of patients who withdrew owing to lack of efficacy was available in three of the five trials (476 patients) with combination of MTX+LEF, ${ }^{20} \mathrm{MTX}+\mathrm{CSA}^{19}$ and MTX+ IM gold $^{21}$ (fig B, online only), showing significantly fewer patient withdrawals than in the MTX monotherapy group with $\mathrm{RR}=0.42(95 \%$ CI 0.21 to 0.84$)$. However, the number of patients who withdrew because of toxicity was significantly increased 1.89 (95\% CI 1.05 to 3.41) (fig C, online only).

Non-MTX DMARD inadequate response, step-up design

The ACR responses were available in two of eight trials (158 patients) that compared MTX mono with MTX combo therapies in non-MTX inadequate responders (fig 4). Only the pooled ACR 20 showed a significant benefits for the combination of $\mathrm{MTX}+\mathrm{SSZ}^{31}$ and MTX+bucillamine (BUC) ${ }^{30}$ over monotherapy with $\mathrm{RR}=1.85$ (95\% CI 1.21 to 2.83). There were no data on ACR remission.

The EULAR response criteria were available for one of these two studies ${ }^{31}$ (fig D, online only) and showed no statistically significant different between two groups.
Figure 3 American College of Rheumatology (ACR) response: MTX combination vs MTX monotherapy in MTX inadequate response group. CSA, ciclosporin; IM gold, intramuscular gold; LEF, leflunomide; LEV, levofloxacin; MTX, methotrexate.

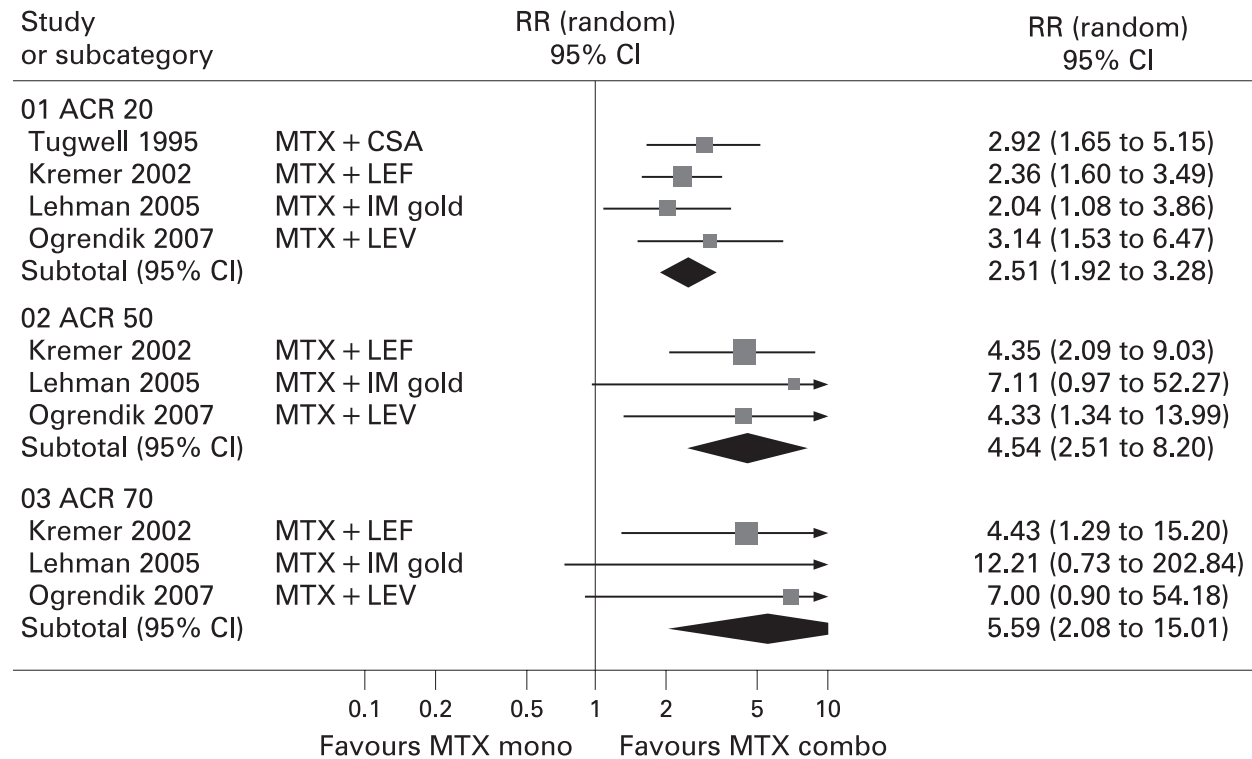


Figure 4 American College of Rheumatology (ACR) response: MTX combination vs MTX monotherapy in nonMTX inadequate response group. BUC, bucillamine; MTX, methotrexate; SSZ, sulfasalazine.

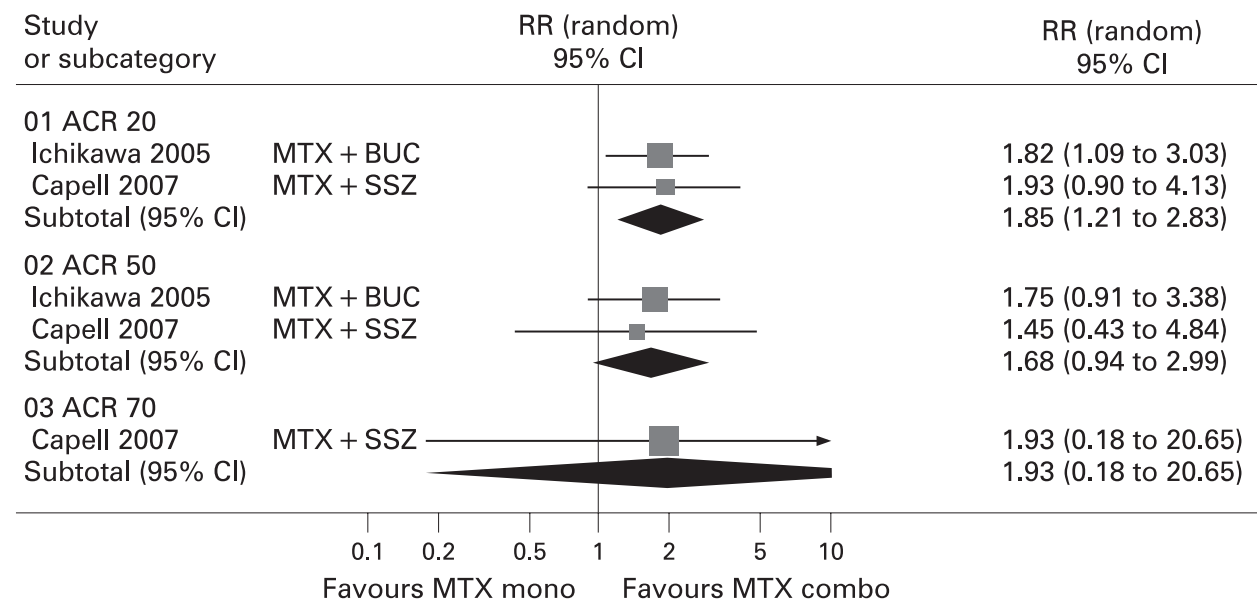

The number of patients who withdrew owing to lack of efficacy was available in five of eight trials (329 patients) with combination of $\mathrm{MTX}+$ chloroquine (CQ), ${ }^{26} \mathrm{MTX}+\mathrm{SSZ}+$ hydroxychloroquine (HCQ), ${ }^{33} \mathrm{MTX}+\mathrm{SSZ},{ }^{31} \mathrm{MTX}+\mathrm{BUC}^{30}$ and MTX+ previous DMARDs (BUC, D-penicillamine and IM gold). ${ }^{29}$ MTX combination therapy yielded significantly fewer patient withdrawals than monotherapy with $R R=0.37$ and 95\% CI 0.16 to 0.87 (fig B, online only).

\section{Toxicity}

Number of total or individual reported adverse events

The azathioprine ${ }^{25}$ and IM gold ${ }^{21}$ MTX combinations increased the risk of the number of total side effects $\mathrm{RR}=1.67(95 \% \mathrm{CI}$ 1.21 to 2.3 ) and $\mathrm{RR}=2.61$ (95\% CI 1.22 to 5.55$)$, respectively. The sulfasalazine $e^{561627}$ and leflunomide ${ }^{20}$ MTX combinations increased the risk of gastrointestinal (GI) side effects $(R R=1.75$, $95 \%$ CI 1.14 to 2.67 and $\mathrm{RR}=1.67,95 \%$ CI 1.17 to 2.4 , respectively). The leflunomide MTX combination $^{20}$ also increased the risk of an abnormal liver function test with $\mathrm{RR}=4.3$ (95\% CI 2.58 to 7.15$)$.

\section{Withdrawal due to adverse reaction}

In 17 of the 19 trials (1624 patients: 824 in combination group vs 800 monotherapy group) combination therapy resulted in more withdrawal due to adverse reactions than monotherapy but the differences were significant only for the $\mathrm{CSA}^{41719}$ and azathioprin $e^{24}$ combinations with $\mathrm{RR}=1.88,95 \%$ CI 1.02 to 3.50) and $\mathrm{RR}=5.18$ (95\% CI 1.58 to16.96), respectively (fig 5).

\section{Combined withdrawal due to lack of efficacy and toxicity (fig 6)} Our primary analysis was based on withdrawals for both efficacy and safety; data were available for 13 of the 19 trials. In DMARD naive patients as well as in MTX inadequate responders pooled results showed no advantage of combination therapy over MTX monotherapy $(\mathrm{RR}=1.16,95 \%$ CI 0.70 to 1.93 and $\mathrm{RR}=0.86,95 \% \mathrm{CI} 0.49$ to 1.51 , respectively). The nonMTX DMARD inadequate responders also showed no advantage of combination therapy ( $R R=0.75,95 \%$ CI 0.41 to 1.35 ). However, there was significant heterogeneity in this group $\left(\mathrm{I}^{2}=57.4 \%\right)$ with one important outlier: the combination of MTX+SSZ+HCQ showed a better efficacy/toxicity ratio than MTX alone with $\mathrm{RR}=0.3$ (95\% CI 0.14 to 0.65$)$.

\section{DISCUSSION}

Despite the introduction of new biological treatments, MTX alone or in combination with other traditional DMARDs remain the recommended first-line treatments for most patients with RA. Our systematic review examined their respective risks and benefits. The simplest criterion of benefit/risk ratio for drug evaluation is whether a drug is stopped owing to inefficacy or AEs. These data were available for 13/19 trials and therefore represent the most powerful results from our meta-analysis. Overall, there were no benefits of MTX combo over monotherapy either within the three design strategies or across all trials ( $R R=0.89,95 \%$ CI 0.66 to 1.21) (fig 6). However, one study of the combination MTX, SSZ and HCQ showed better efficacy/toxicity ratio than MTX alone with $\mathrm{RR}=0.3(95 \% \mathrm{CI}$ 0.14 to 0.65$)$.

Outcome measures other than withdrawals were not reported consistently across trials. In the "DMARD naïve, parallel strategy" ACR responses showed a significant improvement for the combination therapies only for the ACR 70 but with increasing risk of withdrawals due to toxicity. Additionally, none of the trials that reported other composite or single outcome measures could demonstrate a benefit of an initial course of combination therapy over MTX monotherapy in DMARD naïve patients.

In the "MTX inadequate response, step-up strategy" four trials that reported ACR responses showed that combination therapy was significantly more effective than MTX monotherapy (with an equally significant increase in risk of withdrawal for toxicity). These trials, however, do not reflect current practice. The dose of MTX (7-15 mg/week) is lower than current use and patients randomised to the MTX monotherapy arm continued to receive the same inadequate low dose of MTX. In actual practice doctors would increase the dose of MTX or change to parenteral administration before adding another DMARD. Therefore, the current evidence in patients with inadequate response to MTX is inconclusive pending results from new trials that compare maximum doses of MTX monotherapy with combination therapies.

In the "non-MTX DMARDs inadequate response, step-up strategy" only two studies ${ }^{30} 31$ were available for the ACR response analysis. Unfortunately, no conclusions can be reached. In Capell's study, patients for whom SSZ 2 g/day had already failed were randomised to receive MTX alone or MTX + the "same dose" of SSZ; so in reality this was a study comparing MTX in both arms. The second is a trial of bucillamine which is not commonly used in North America or Europe.

For toxicity analyses, GI and liver adverse events were higher in the sulfasalazine and leflunomide MTX combinations but did 
Figure 5 Withdrawal due to adverse reaction stratified by combination of disease-modifying antirheumatic drugs (DMARDs). AZA, azathioprine; BUC, bucillamine; CSA, ciclosporin; $\mathrm{CQ}$, chloroquine; $\mathrm{HCO}$, hydroxychloroquine; IM gold, intramuscular gold; LEF, leflunomide; MTX, methotrexate; SSZ, sulfasalazine.
Study or subcategory

RR (random) 95\% Cl

$\mathrm{RR}$ (random) 95\% Cl

01 MTX + SSZ

Haagsma 1997

Dougados 1999

Islam 2000

Tascioglu 2003

Capell 2007

Subtotal $(95 \% \mathrm{CI})$

Total events: 33 (MTX combo), 26 (MTX mono)

Test for heterogeneity: $\chi^{2}=3.80, d f=4(p=0.43), 1^{2}=0 \%$

Test for overall effect: $Z=0.70(p=0.49)$

$02 \mathrm{MTX}+\mathrm{SSZ}+\mathrm{HCO}$

O'Dell 1996

Subtotal $(95 \% \mathrm{CI})$

Total events: 3 (MTX combo), 7 (MTX mono)

Test for heterogeneity: not applicable

Test for overall effect: $Z=1.08(p=0.28)$

$03 \mathrm{MTX}+\mathrm{CO}$

Ferraz 1994

Subtotal $(95 \% \mathrm{CI})$

Total events: 3 (MTX combo), 1 (MTX mono)

Test for heterogeneity: not applicable

Test for overall effect: $Z=0.97(p=0.33)$

$04 \mathrm{MTX}+\mathrm{CSA}$

Tugwell 1995

Marchesoni 2003

Hetland 2006

Subtotal $(95 \% \mathrm{Cl})$

Total events: 27 (MTX combo), 14 (MTX mono)

Test for heterogeneity: $\chi^{2}=0.92, d f=2(p=0.63), I^{2}=0 \%$

Test for overall effect: $Z=2.01(p=0.04)$

$05 \mathrm{MTX}+\mathrm{AZA}$

Willkens 1992

Subtotal $(95 \% \mathrm{CI})$

Total events: 16 (MTX combo), 3 (MTX mono)

Test for heterogeneity: not applicable

Test for overall effect: $Z=2.72(p=0.007)$

$06 \mathrm{MTX}+\mathrm{LEF}$

Kremer 2002

Subtotal $(95 \% \mathrm{Cl})$

Total events: 16 (MTX combo), 9 (MTX mono)

Test for heterogeneity: not applicable

Test for overall effect: $Z=1.50(p=0.13)$

$07 \mathrm{MTX}+\mathrm{IM}$ gold

Lehman 2005

Subtotal $(95 \% \mathrm{CI})$

Total events: 4 (MTX combo), 1 (MTX mono)

Test for heterogeneity: not applicable

Test for overall effect: $Z=0.96(p=0.34)$

$08 \mathrm{MTX}+$ antibiotics

O'Dell 2006

Ogrendik 2007

Subtotal $(95 \% \mathrm{Cl})$

Total events: 7 (MTX combo), 2 (MTX mono)

Test for heterogeneity: $\chi^{2}=0.10, d f=1(p=0.75), 1^{2}=0 \%$

Test for overall effect: $Z=0.92(p=0.36)$

$09 \mathrm{MTX}+\mathrm{BUC}$

Ichikawa 2005

Subtotal $(95 \% \mathrm{Cl})$

Total events: 6 (MTX combo), 2 (MTX mono)

Test for heterogeneity: not applicable

Test for overall effect: $Z=1.38(p=0.17)$

10 MTX + miscellaneous DMARDs

Hanyu 1999

Subtotal $(95 \% \mathrm{Cl})$

Total events: 6 (MTX combo), 4 (MTX mono)

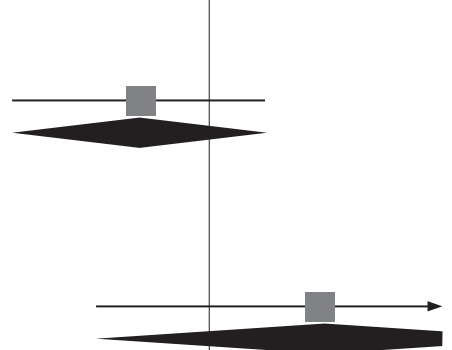

$0.50(0.14$ to 1.76$)$

$0.50(0.14$ to 1.76$)$

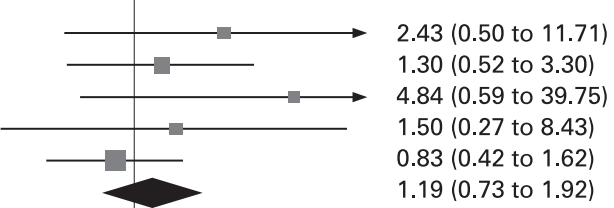

$0.83(0.42$ to 1.62$)$
$1.19(0.73$ to 1.92$)$

$3.00(0.33$ to 27.42$)$

$3.00(0.33$ to 27.42$)$

$3.62(0.82$ to 16.03$)$

1.57 (0.64 to 3.85$)$

$1.88(1.02$ to 3.50$)$

Test for heterogeneity: not applicable

Test for overall effect: $Z=0.63(p=0.53)$

Favours MTX combo Favours MTX mono 
Figure 6 Withdrawal due to either lack of efficacy or toxicity: MTX combination vs MTX monotherapy in diseasemodifying antirheumatic drug (DMARD) naïve, MTX inadequate response and nonMTX inadequate response groups. BUC, bucillamine, $\mathrm{CO}$, chloroquine; CSA, ciclosporin; DOXY, doxycycline; HCQ, hydroxychloroquine; IM gold, intramuscular gold; LEF, leflunomide; MTX, methotrexate; SSZ, sulfasalazine.
Study

or subcategory $\mathrm{RR}$ (random) $95 \% \mathrm{Cl}$

$\mathrm{RR}$ (random) $95 \% \mathrm{Cl}$

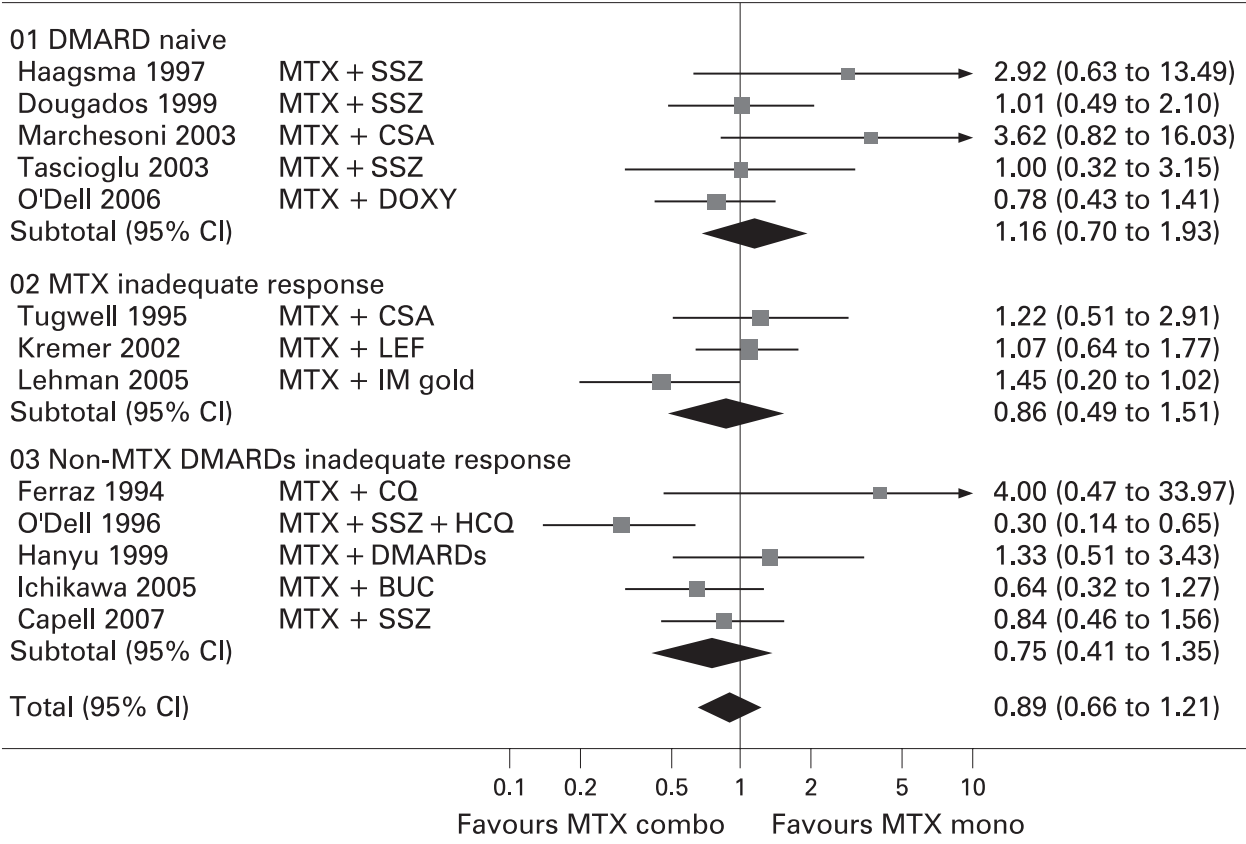

not lead to significant differences in withdrawal rates. The total number of side effects was higher with gold and azathioprine MTX combinations. Withdrawal rates due to adverse reactions were higher in all the combination therapies, but the differences were significant only for the combinations of MTX+ciclosporin and MTX+azathioprine.

There are important limitations to our analyses; many of the studies included a small number of patients; most used lower doses of MTX than in current practice and had different length of follow-up and several studies were done with drugs that are not commonly used (bucillamine, doxycycline, levofloxacin, chloroquine, IM gold and ciclosporin). Furthermore, most of the combinations were studied in only one or two trials, except the combination MTX+SSZ, which included five trials. Also, outcome measures were inconsistently reported; European trials used DAS or DAS28 while others reported ACR responses, some (studies before 2000) reported only individual clinical and laboratory outcomes. All these limitations complicate the pooling of results across studies. Nonetheless, this meta-analysis presents useful information, particularly when looking at total withdrawal rates where combination across a number of studies is possible.

Three previous systematic reviews ${ }^{3436}$ and two meta-analyses $^{37}{ }^{38}$ compared DMARD monotherapy with combination therapy. Felson et al (1994) ${ }^{37}$ and Verhoeven et al (1998) ${ }^{35}$ concluded that combination DMARD therapy does not substantially improve efficacy and toxicity is increased; this is consistent with our overall results that included more recent trials. Hochberg et al (2001) ${ }^{36}$ included only MTX inadequate responder studies and found that ACR responses improved significantly when a second DMARD was added. Choy et al $(2005)^{38}$ reached the same conclusion in this subgroup of patients based on analysis of withdrawals but added that improved efficacy is associated with an increased risk of adverse events. Donahue et al (2008) $)^{34}$ reported only on a small subset of our included trials (mostly of sulfasalazine combinations) and the remainder of his and Choy's data cannot be compared with our study because they included biologic agents as well as monotherapies with non-biological DMARDs other than MTX.

In summary, when the balance of efficacy and toxicity is taken into account, the evidence from our systematic review showed no significant advantage of the MTX combination versus monotherapy; only one study with the specific combination of MTX+SSZ+HCQ showed a better efficacy/toxicity ratio than MTX alone. Adding leflunomide to MTX non-responders improved efficacy but increased the risk of GI side effects and liver toxicity. Withdrawals because of toxicity varied but were most significant with ciclosporin and azathioprine combinations. Trials are needed that compare currently used MTX doses and combination therapies.

Acknowledgements: We thank Professor Maxime Dougados, Professor Loreta Carmona, Professor Desiree van der Heijde, Assistant Professor Vivian Bykerk, Dr Carine Salliot, Dr Karen Visser, Dr Estebaliz Loza, Dr Juan-Antonio Martinez and the 3E scientific committee for their suggestions and Amy Faulkner for the literature search.

Funding: This work was supported by Abbott with an unrestricted educational grant. Abbott had no role in the study design, literature search, data collection, data analysis, data interpretation or writing of this report.

Competing interests: CB holds a Canada Research Chair in knowledge transfer for musculoskeletal care.

\section{REFERENCES}

1. Möttönen T, Hannonen $P$, Leirisalo-RepoM, Nissilä M, Kautiainen $H$, Korpela $\mathrm{M}$, et al. Comparison of combination therapy with single-drug therapy in early rheumatoid arthritis: a randomised trial Lancet 1999;353:1568-73.

2. Goekoop-Ruiterman YPM, de Vries-Bouwstra J, Allaart C, van Zeben D, Kerstens PJSM, Hazes J, et al. Clinical and radiographic outcomes of four different treatment strategies in patients with early rheumatoid arthritis (the BeSt study): a randomized, controlled trial. Arthritis Rheum 2005;52:3381-90.

3. Goekoop-Ruiterman YPM, de Vries-Bouwstra J, Allaart C, van Zeben D, Kerstens PJSM, Hazes J, et al. Comparison of treatment strategies in early rheumatoid arthritis: a randomized trial. Ann Intern Med 2007;146:406-15.

4. Marchesoni A, Battafarano N, Arreghini M, Gallazzi M, Tosi S. Radiographic progression in early rheumatoid arthritis: a 12-month randomized controlled study comparing the combination of cyclosporin and methotrexate with methotrexate alone. Rheumatology (Oxford) 2003;42:1545-9.

5. Tascioglu F, Oner C, Armagan 0 . Comparison of low dose methotrexate and combination therapy with methotrexate and sulphasalazine in the treatment of early rheumatoid arthritis. J Rheumatol Med Rehab 2003;14:142-9. 
6. Dougados M, Combe B, Cantagrel A, Goupille P, Olive P, Schattenkirchner M, et al. Combination therapy in early rheumatoid arthritis: a randomised, controlled, double blind 52 week clinical trial of sulphasalazine and methotrexate compared with the single components. Ann Rheum Dis 1999:58:220-5.

7. Visser K, Katchamart W, Loza E, Martinez-Lopez J, Salliot C, Trudeau J, et al. Multinational evidence-based recommendations for the use of methotrexate in rheumatic disorders with a focus on rheumatoid arthritis: integrating systematic literature research and expert opinion of a broad international panel of rheumatologists in the 3E Initiative. Ann Rheum Dis 2009:68:1086-93.

8. Felson D, Anderson JJ, Boers M, Bombardier C, Chernoff M, Fried B, et al. The American College of Rheumatology preliminary core set of disease activity measures for rheumatoid arthritis clinical trials. Arthritis Rheum 1993:36:729-40.

9. Felson D, Anderson J, Boers M, Bombardier C, Furst D, Goldsmith C, et al. American College of Rheumatology preliminary definition of improvement in rheumatoid arthritis. Arthritis Rheum 1995;38:727-35.

10. Pinals R, Alfonse T, Larsen R. Preliminary criteria for clinical remission in rheumatoid arthritis. Arthritis Rheum 1981;24:1308-15.

11. van der Heijde DM, van't Hof MA, van Riel PL, van Leeuwen MA, van Rijswijk MH, van de Putte LB. Validity of single variables and composite indices for measuring disease activity in rheumatoid arthritis. Ann Rheum Dis 1992:51:177-81.

12. Prevoo MLL, van't Hof MA, Kuper HH, van Leeuwen MA, van de Putte LB, van Riel PLCM. Modified disease activity scores that include twenty-eight-joint counts development and validation in a prospective longitudinal study of patients with rheumatoid arthritis. Arthritis Rheum 1995;38:44-8.

13. van Gestel AM, Prevoo MLL, van't Hof MA, van Rijswijk MH, van de Putte LBA, van Riel PLCM. Development and validation of the European League Against Rheumatism response criteria for rheumatoid arthritis. Comparison with the preliminary American College of Rheumatology and the World Health Organization/International League Against Rheumatism Criteria. Arthritis Rheum 1996;39:34-40.

14. van Tulder M, Furlan A, Bombardier C, Bouter L. The Editorial Board of the Cochrane Collaboration Back Review G. Updated method guidelines for systematic reviews in the Cochrane collaboration back review group. Spine 2003;28:1290-9.

15. Alderson P, Green S. Meta-analysis of continuous data: deciding on a change (from baseline). Cochrane Collaboration: Open learning material for reviewers, 2002. Available at http://www.cochrane-net.org/openlearning/HTML/mod0.htm (additional module A1, accessed 16 April 2009)

16. Haagsma CJ, van Riel PL, de Jong AJ, van de Putte LB. Combination of sulphasalazine and methotrexate versus the single components in early rheumatoid arthritis: a randomized, controlled, double-blind, 52 week clinical trial. Br J Rheumatol 1997; 36:1082-8

17. Hetland ML, Stengaard-Pedersen K, Junker P, Lottenburger T, Ellingsen T, Andersen LS, et al. Combination treatment with methotrexate, cyclosporine, and intraarticular betamethasone compared with methotrexate and intraarticular betamethasone in early active rheumatoid arthritis: an investigator-initiated, multicenter, randomized, doubleblind, parallel-group, placebo-controlled study. Arthritis Rheum 2006;54:1401-9.

18. O'Dell JR, Elliott JR, Mallek JA, Mikuls TR, Weaver CA, Glickstein S, et al. Treatment of early seropositive rheumatoid arthritis: doxycycline plus methotrexate versus methotrexate alone. Arthritis Rheum 2006;54:621-7.

19. Tugwell P, Pincus T, Yocum D, Stein M, Gluck O, Kraag G, et al. Combination therapy with cyclosporine and methotrexate in severe rheumatoid arthritis. The MethotrexateCyclosporine Combination Study Group. N Engl J Med 1995;333:137-41.

20. Kremer JM, Genovese MC, Cannon GW, Caldwell JR, Cush JJ, Furst DE, et al Concomitant leflunomide therapy in patients with active rheumatoid arthritis despite stable doses of methotrexate. A randomized, double-blind, placebo-controlled trial. Ann Intern Med 2002;137:726-33.

21. Lehman AJ, Esdaile JM, Klinkhoff AV, Grant E, Fitzgerald A, Canvin J. A 48-week, randomized, double-blind, double-observer, placebo-controlled multicenter trial of combination methotrexate and intramuscular gold therapy in rheumatoid arthritis: results of the METGO study. Arthritis Rheum 2005;52:1360-70.
22. Jarrett SJ, Conaghan PG, Sloan VS, Papanastasiou P, Ortmann CE, O'Connor PJ, et al. Preliminary evidence for a structural benefit of the new bisphosphonate zoledronic acid in early rheumatoid arthritis. Arthritis Rheum 2006;54:1410-4.

23. Ogrendik M. Levofloxacin treatment in patients with rheumatoid arthritis receiving methotrexate. South Med J 2007;100:135-9.

24. Willkens RF, Urowitz MB, Stablein DM, McKendry RJ Jr, Berger RG, Box JH, et al. Comparison of azathioprine, methotrexate, and the combination of both in the treatment of rheumatoid arthritis. A controlled clinical trial. Arthritis Rheum 1992:35:849-56.

25. Willkens RF, Sharp JT, Stablein D, Marks C, Wortmann R. Comparison of azathioprine, methotrexate, and the combination of the two in the treatment of rheumatoid arthritis. A forty-eight-week controlled clinical trial with radiologic outcome assessment. Arthritis Rheum 1995;38:1799-806.

26. Ferraz MB, Pinheiro GR, Helfenstein M, Albuquerque E, Rezende $C$, Roimicher $L$, et al. Combination therapy with methotrexate and chloroquine in rheumatoid arthritis. A multicenter randomized placebo-controlled trial. Scand J Rheumatol 1994;23:231-6.

27. Haagsma CJ, van Riel P, de Rooij D, Vree TB, Russel FJM, van't Hof MA, et al. Combination of methotrexate and sulphasalazine vs methotrexate alone: a randomized open clinical trial in rheumatoid arthritis patients resistant to sulphasalazine therapy. Br J Rheumatol 1994;33:1049-55.

28. O'Dell JR, Haire CE, Erikson N, Drymalski W, Palmer W, Eckhoff PJ, et al. Treatment of rheumatoid arthritis with methotrexate alone, sulfasalazine and hydroxychloroquine, or a combination of all three medications. N Engl J Med 1996;334:1287-91.

29. Hanyu T, Arai K, Ishikawa H. Long-term methotrexate (MTX) combination therapy versus MTX alone for active rheumatoid arthritis. Jpn J Rheumatol 1999:9:31-44.

30. Ichikawa Y, Saito T, Yamanaka H, Akizuki M, Kondo H, Kobayashi S, et al. Therapeutic effects of the combination of methotrexate and bucillamine in early rheumatoid arthritis: a multicenter, double-blind, randomized controlled study. Mod Rheumatol 2005;15:323-8.

31. Capell HA, Madhok R, Porter DR, Munro RAL, Mclnnes IB, Hunter JA, et al. Combination therapy with sulfasalazine and methotrexate is more effective than either drug alone in patients with rheumatoid arthritis with a suboptimal response to sulfasalazine: results from the double-blind placebo-controlled MASCOT study. Ann Rheum Dis 2007;66:235-41.

32. Islam MN, Alam MN, Haq SA, Moyenuzzaman M, Patwary MI, Rahman MH. Efficacy of sulphasalazine plus methotrexate in rheumatoid arthritis. Bangladesh Med Res Counc Bull 2000;26:1-7.

33. O'Dell JR, Haire C, Erikson N, Drymalski W, Palmer W, Maloley P, et al. Efficacy of triple DMARD therapy in patients with RA with suboptimal response to methotrexate. J Rheumatol 1996;44:72-4.

34. Donahue KE, Gartlehner G, Jonas DE, Lux LJ, Thieda P, Jonas BL, et al. Systematic review: comparative effectiveness and harms of disease-modifying medications for rheumatoid arthritis. Ann Intern Med 2008;148:124-34

35. Verhoeven AC, Boers M, Tugwell P. Combination therapy in rheumatoid arthritis: updated systematic review. Br Rheumatol 1998;37:612-9.

36. Hochberg MC, Tracy JK, Flores RH. 'Stepping-up' from methotrexate: a systematic review of randomised placebo controlled trials in patients with rheumatoid arthritis with an incomplete response to methotrexate. Ann Rheum Dis 2001;60:iii51-4.

37. Felson DT, Anderson JJ, Meenan RF. The efficacy and toxicity of combination therapy in rheumatoid arthritis: A meta-analysis. Arthritis Rheum 1994;37:1487-91.

38. Choy EHS, Smith C, Dore CJ, Scott DL. A meta-analysis of the efficacy and toxicity of combining disease-modifying anti-rheumatic drugs in rheumatoid arthritis based on patient withdrawal. Rheumatology (Oxford) 2005;44:1414-21.

\section{APPENDIX}

The results and figures of the search strategy (appendix 1), efficacy (EULAR response, withdrawal due to lack of efficacy, significant results of continuous data) and toxicity (appendix 2) are available on the website. 